\title{
Consumo colaborativo e relacional no contexto do turismo: a proposição de um modelo entre a sociabilidade e a hospitalidade em rede ${ }^{1}$
}

\section{Collaborative and relational consumption in the tourism context: a proposed model between the sociability and the hospitality network}

\section{El consumo colaborativo y relacional dentro del turismo: proponer un modelo de sociabilidad y de la hospitalidad en la red}

\author{
Beatriz Gondim Matos ${ }^{2}$ \\ Maria de Lourdes de Azevedo Barbosa ${ }^{3}$ \\ Mariana Bueno de Andrade Matos ${ }^{4}$
}

\begin{abstract}
Resumo
A revolução tecnológica vem influenciando a forma como as pessoas se relacionam e como consomem. Na atividade turística, percebe-se que as práticas sociais e econômicas estão cada vez mais associadas, surgindo a partir daí um tipo de consumo denominado colaborativo, com características de base relacional e que podem ocorrer tanto na interação presencial quanto virtual, em conexão e com a participação de atores (governo, empresas, a comunidade receptora e os turistas) que integram um destino turístico. Assim, realizou-se uma revisão de literatura baseada em reflexões sobre o consumo colaborativo e relacional, sociabilidade e hospitalidade em rede no contexto do turismo. Este artigo foi estruturado a partir de três objetivos: (1) compreender os conceitos de consumo colaborativo e sharing; (2) descrever a sociabilidade e hospitalidade em rede propostas por Wittel (2001) e Molz (2014), respectivamente; (3) propor uma reflexão dos aspectos fundamentais que caracterizam o consumo colaborativo e relacional no contexto do turismo. Como resultado, apresenta-se um quadro interpretativo do consumo colaborativo e relacional no contexto do turismo, que pode servir como base e estimulo para um maior aprofundamento e pesquisa sobre o tema proposto.
\end{abstract}

\footnotetext{
${ }^{1}$ Artigo revisado e ampliado. Originalmente apresentado no XII Seminário 2015 da Associação Nacional de Pesquisa e Pós-Graduação em Turismo ANPTUR.

${ }^{2}$ Doutoranda em Administração na Universidade Federal de Pernambuco/UFPE. Mestre em Administração e Controladoria pela Universidade Federal do Ceará/UFC. Graduada em Administração de Empresas pela Universidade Estadual do Ceará/UECE. Professora do Curso de Administração das Faculdades Integradas Barros Melo/AESO gm.beatriz@gmail.com

${ }^{3}$ Doutora em Administração pela Universidade Federal de Pernambuco/UFPE. Professora do Departamento de Hotelaria e Turismo/DHT e do Programa de Pós-Graduação em Administração/PROPAD da UFPE. lourdesbarbosa@gmail.com.

${ }^{4}$ Mestre e Doutoranda em Administração e graduada em Hotelaria pela Universidade Federal de Pernambuco (UFPE). mbuenodeandrade@gmail.com
} 
Palavras-chave: consumo colaborativo e relacional; sociabilidade em rede; hospitalidade em rede; turismo.

\begin{abstract}
The technological revolution has changed the ways how people relate and how they consume. In the tourism context, we can see that social and economic practices are increasingly associated and this is arising a kind of consumption known as collaborative, relational based and that can occur either by virtual interaction or by physical attendance, in connection and with the participation of actors (government, business, the receiving community and tourists) that are part of a tourist destination. Therefore, the essay brought a literature review based on reflections on the collaborative and relational consumption, sociability and hospitality network within tourism. This article was structured around three objectives: (1) understand the concepts of collaborative consumption and sharing; (2) describe the network sociability and hospitality offered by Wittel (2001) and Molz (in 2014), respectively; (3) to propose fundamental aspects that feature the collaborative and relational consumption in the tourism context. As a result, it presents an interpretive framework of the collaborative and relational consumption within tourism, which can serve as the basis and stimulus for further development and research on the theme.
\end{abstract}

Keywords: collaborative and relational consumption; network sociability; network hospitality; tourism.

\title{
Resumen
}

La revolución tecnológica ha cambiado la forma cómo las personas se relacionan y consumen. En el contexto del turismo, es visible que las prácticas económicas y sociales se asocian progresivamente con la finalidad de complementarse y, de esta asociación, se da el surgimiento de una especie de consumo conocida como colaborativo, con fundación relacional y que puede ocurrir en la interacción física y virtual, en la conexión y con la participación de actores (gobierno, empresas, comunidad receptora y turistas) que son parte de un destino turístico. Así, se llevó a cabo una revisión de la literatura sobre la base de las reflexiones sobre el consumo colaborativo y relacional, la sociabilidad y la hospitalidad en red no turismo. Este artículo se estructura en torno a tres objectivos: (1) entender los conceptos de consumo colaborativo y el sharing; (2) describir la sociabilidad y la hospitalidad en red ofrecida por Wittel (2001) y Molz (2014), respectivamente; (3) proponer aspectos fundamentales que caracterizan el consumo colaborativo y relacional en el contexto del turismo. Como resultado, se presenta un framework interpretativo del consumo colaborativo y relacional dentro del turismo, que puede servir de base y estímulo para el desarrollo y la investigación sobre el tema.

Palabras clave: el consumo colaborativo y relacional; sociabilidad en red; la hospitalidad en red; turismo.

\section{Introdução}

A revolução ocorrida nas últimas décadas, em função do desenvolvimento de novas tecnologias, foi acompanhada pela necessidade de uma maior conexão entre os indivíduos. 
Conforme destaca Shirky (2011), o uso de uma tecnologia é menos determinado pelo próprio instrumento do que pela rede (neste caso, a internet) que permite um maior acesso entre as pessoas. Fazendo uma breve retrospectiva, nota-se que a televisão enquanto tecnologia, mesmo tendo avançado em seus recursos, não permitiu o mesmo nível de interação, conexão e associação que as plataformas e redes da internet permitiram entre os membros que nela interagem. Assim, a necessidade de conexão entre indivíduos é um desejo que a televisão, como substituto social, por exemplo, não possibilitou. Isso ressalta que nem todo avanço tecnológico implica em mudança social e, que, a apropriação do uso das tecnologias pelos indivíduos é que revela mudanças na sociedade.

Reforçando o argumento anterior, e trazendo essa reflexão para o campo das viagens e do turismo, Urry (2003) ressalta que, mesmo com o aumento e proliferação de dispositivos de comunicação que poderiam substituir alguns deslocamentos (ex. museus virtuais, plataformas de comunicação, etc.), as pessoas passaram a viajar mais, muito em função da necessidade de manutenção da vida social e com o intuito de criar espaços sociais próprios das viagens.

O reforço da base relacional entre pessoas leva a discussão sobre a sociedade que se organiza em redes, que se apresenta com abordagens diversas. Uma delas é apresentada por Castells (1996), um dos precursores na conceituação do termo Sociedade em Rede (Network Society), que a definiu como estruturas abertas, altamente dinâmicas, suscetíveis à inovação, baseadas na globalização e na descentralização. Essa definição inspirou e forneceu a base para que outros teóricos desenvolvessem perspectivas decorrentes dessas premissas.

$\mathrm{Na}$ sociedade em rede, deve-se ressaltar, que o aumento das conexões entre as pessoas possibilitou o surgimento do que se denominou consumo colaborativo e compartilhamento. Observa-se que as perspectivas que conceituam esses construtos têm a troca e o que é trocado como elementos centrais: a colaboração é uma forma de realizar transações comerciais e/ou compartilhar tangíveis (transferência de propriedade) mediada pela tecnologia (BELK, 2007, 2010; BOTSMAN, ROGERS, 2010; MANZINI, 2010).

Complementando o pensamento acima, autores como Brabham (2008), Rowley, KupiecTeahan e Leeming (2007), Tapscott e Williams (2008) apontam para conceitos e abordagens que focam a colaboração online, mediada pela tecnologia, como vetor para a criação e desenvolvimento de conceitos, sistemas, serviços, e ideias associadas à participação ou colaboração online de usuários, consumidores e outros grupos. 
Algumas características dos conceitos associados ao consumo colaborativo encontrados na literatura, não apresentam a necessidade de conexão entre os indivíduos para além da participação e colaboração online, bem como aspectos que ultrapassam a transferência de propriedade. Este trabalho, portanto, busca avançar nessas reflexões, na tentativa de contribuir para a evolução no estudo do consumo colaborativo no contex to do turismo.

O turismo apresenta-se como um objeto de estudo rico por ser uma atividade eminentemente relacional e que pode ensejar a apropriação da tecnologia durante todo o processo da experiência turística (desde a escolha do destino, passando pela consulta às redes e plataformas que promovem serviços e associação entre turistas e locais, até a avaliação dos locais visitados, etc.). Esse contexto levou a proposição de um quadro compreensivo para caracterizar esse tipo de consumo colaborativo e relacional que foi desenvolvido a partir de abordagens sociológicas, por estas serem capazes de melhor explicar os fatores sociais e relacionais que estão presentes nesse tipo de interação.

Para o desenvolvimento do tema proposto este ensaio teórico foi divido em quatro partes. Inicialmente são apresentados os principais conceitos de consumo colaborativo e compartilhamento; na sequência é discutido o que se configura como a sociabilidade e hospitalidade em rede; posteriormente, são propostos os aspectos fundamentais que caracterizam o consumo colaborativo e relacional no contexto do turismo e, finalmente, são tecidas as considerações finais.

\section{Consumo colaborativo e compartilhamento (sharing)}

O consumo colaborativo e o compartilhamento (sharing) são tratados sob o mesmo conceito, principalmente a partir de uma visão utilitarista, desconsiderando, em alguns aspectos, a perspectiva social dessa prática de consumo. Nesse sentido, alguns argumentos, de diferentes autores, são trabalhados neste tópico para melhor ilustrar este argumento.

O termo consumo colaborativo foi usado pela primeira vez por Felson e Speath (1978). À época consumo colaborativo foi tomado como rotinas comunitárias de consumo. Apesar desta menção inicial, os autores contemporâneos, a serem tratados na sequencia deste tópico, adotaram concepções bastante diferenciadas ao centrarem às discussões do consumo colaborativo como 
estando associado às práticas de colaboração e consumo a partir da apropriação do uso da internet.

Para os praticantes de Marketing e Negócios, o consumo colaborativo, a economia colaborativa, e o sharing ou compartilhamento, são apresentados como uma nova prática comercial e inovadora capaz de orientar a economia para um mundo melhor em termos de redistribuição de mercados, economia da abundância e centrada no social (Botsman \& Rogers, 2010). Complementando, os mesmos ainda caracterizam as práticas de consumo colaborativo em três tipos, a saber: sistema de serviço de produtos (compartilhamento para o acesso ao uso de produtos - carros, lavandeiras automáticas, bicicletas), mercados de redistribuição (compartilhamento no sentido de doação ou troca por outros artigos de semelhante ou igual valor - troca de livros por outros livros, doação de objetos que não se usa mais) e estilos de vida colaborativos (compartilhamento de intangíveis baseados na associação de pessoas para este fim - espaços de trabalho, hospitalidade como o CouchSurfing e Airbnb ${ }^{5}$, habilidades, etc).

Por outro lado, na perspectiva acadêmica, há distinção entre consumo colaborativo e compartilhamento ou sharing. De acordo com Belk (2007, 2010), o compartilhamento é quando há o ato ou processo de transferir o que é seu a outros ou o ato de tomar o que é dos outros para seu uso. Podem ser compartilhados tangíveis ou intangíveis, tais como ideias, valores e tempo. Deste conceito, Belk $(2007,2010)$ exclui as atividades de compartilhamento que não envolvem uma compensação financeira ou equivalente, tal como ocorre no Couchsurfing ${ }^{6}$, onde não há transação financeira entre os membros.

Além da distinção entre compartilhamento e consumo colaborativo, Belk (2013) define o consumo colaborativo como caracterizado por pessoas coordenando a aquisição e distribuição de recursos por uma compensação financeira ou um outro tipo de compensação, como troca, permuta ou comércio. Este conceito de consumo colaborativo também exclui atividades que não envolvem alguma outra forma de compensação, como é o caso do Couchsurfing, rede social na qual pessoas oferecem acolhimento em suas residências a indivíduos de outras localidades sem

\footnotetext{
${ }^{5}$ Site que funciona como uma espécie de mercado de hospedagem no qual pessoas anunciam parte ou a totalidade de suas residências ao redor do mundo a viajantes interessados em uma proposta diferenciada. Há cobrança pela hospedagem e serviços que a plataforma oferece.

${ }^{6}$ Rede colaborativa de hospedagem domiciliar mediada pela web. Atualmente congrega 10 milhões de pessoas geograficamente localizadas em 200 mil cidades. Os integrantes se associam em prol de oferecer hospedagem, buscar hospedagem e/ou se disponibilizar para um encontro com turistas que visitam suas cidades. Os serviços, incluindo a hospedagem entre os membros, são gratuitos.
} 
que haja uma recompensa financeira ou outra que se enquadre em um dos tipos mencionados anteriormente.

Enquanto a perspectiva de Belk (2013) ao se referir ao compartilhamento ou ao consumo colaborativo limita-se às trocas de tangíveis ou intangíveis por uma compensação, a de Botsman e Rogers (2010) abrange mais práticas por considerar aquelas em que a compensação não é necessária.

Diante das diferentes perspectivas, relativas a compreensão dos aspectos que definem o consumo colaborativo, verificou-se que, no contexto da atividade turística, especificamente, existem algumas práticas que vão além das compensações de ordem estritamente financeira, de forma direta, e se centram no aspecto relacional entre aqueles que acolhem e os que se hospedam.

É importante destacar que o consumo colaborativo é, antes de tudo, relacional e, portanto, pode envolver trocas (financeiras ou não), exigindo a interação de, pelo menos, duas pessoas e, tanto a produção quanto o compartilhamento de tangíveis (bens) e/ou intangíveis (ideias, tempo, valores e informação) são habilitadas, necessariamente, por uma plataforma que se configura como uma rede.

Sendo imprescindível uma rede para que o consumo colaborativo se concretize, se faz necessário tratar da temática sociabilidade em rede, na medida em que esta pode oferecer subsídios para a proposição de uma alternativa de interpretação do consumo colaborativo e relacional no contexto do turismo.

\section{A sociabilidade e a hospitalidade em rede no contexto do consumo colaborativo}

Este tópico apresenta uma contextualização das abordagens que iniciaram a discussão do movimento de organização em rede baseado em sociabilidade e, a partir daí, introduz uma teorização do consumo colaborativo relacional para o turismo. Essa perspectiva é necessária, na medida em que se parte da proposição de que o consumo colaborativo e relacional é habilitado, antes de tudo, por uma plataforma em que seus membros a significam como rede.

Como já mencionado, Castells (1996) foi o precursor do termo Network Society, definindo sociedades em redes como estruturas abertas, altamente dinâmicas, suscetíveis à inovação, baseadas na globalização e descentralização. A visão macro sociológica da Network Society, inspirou Wittel (2001) a desenvolver uma micro sociologia onde networking é visto 
como uma prática social. A principal preocupação de Wittel (2001) foi estabelecer como são desenvolvidas as redes e que tipo de sociabilidade ou sociality existe na era da informação. Assim, no decorrer deste tópico, busca-se discutir algumas características da Network Sociality e introduzir como esta se relaciona com formas emergentes de consumo colaborativo e relacional.

Wittel (2001) propõe a abordagem das transformações sociais da Network Society sob uma visão não tecno determinística; onde o uso do termo 'comunidade', ao se referir às comunidades virtuais parece confuso, pois não apresenta as mesmas características do termo 'comunidade', utilizado nas Ciências Sociais; e propõe a não distinção entre interações online e offline como pertencentes a realidades distintas. Em resumo, coaduna-se com a visão de Wittel (2001) quando este estabelece que as comunidades sociais e organizacionais não são caracterizadas pelo pertencimento dos indivíduos, mas pela integração e desintegração (indivíduos tanto se associam quanto se dissociam das comunidades - isto implica em um pertencimento temporário); as relações sociais são caracterizadas pelos encontros efêmeros, porém, intensos; e há constante associação entre trabalho e lazer nas suas práticas. Por fim, a Network Sociality proposta pelo autor integra todos os laços sociais que são continuamente produzidos, reproduzidos e consumidos de forma efêmera na Network Society.

Dentro desse contexto de sociedades em rede, é necessário fazer uma ressalva ao termo comunidades virtuais. As plataformas disponíveis nas redes nem sempre se caracterizam como comunidades, entretanto, a medida que seus membros as utilizam, tornam possível sua caracterização como tal, tornando viável o seu estudo na perspectiva comunitária.

Em 2014, Molz reviu algumas proposições de Wittel (2001), a partir dos avanços tecnológicos ocorridos durante esses treze anos, verificou que as plataformas e redes possibilitaram uma maior apropriação social ao uso das características desta sociabilidade constituída em rede.

Molz (2014), argumenta que estão ocorrendo transformações na sociability ou sociabilidade, que permeiam todos os campos de estudo e, a partir dessa constatação, extrapola sua interpretação para a área de hospitalidade. A autora se propõe no seu estudo interpretar a hospitalidade como uma forma de sociabilidade e compreender como esta tem interseção com tecnologias sociais em rede, na medida em que habilitam novas configurações de vida comunal entre amigos e estranhos em comunidades 'globais'. 
A hospitalidade, em essência, traz à discussão a análise das "relações interpessoais como o resgate, a troca do calor humano num ambiente social cada vez mais inóspito, quando não hostil, ressaltando as possibilidades que restam no mundo contemporâneo, de manifestação ou de recriação dos vínculos sociais" (CAMARGO, 2015, p. 46).

A respeito da hospitalidade virtual, Camargo (2003) declarou que nos meios virtuais já há a ubiquidade da relação de hospitalidade, hóspede e visitante, no papel do emissor e do receptor, com todas as consequências que a relação implica. É um convite para a concepção da hospitalidade nas plataformas da web e uma tendência o seu desenvolvimento pelos órgãos públicos, empresas, cidadãos e indivíduos. A hospitalidade virtual surge como uma preocupação em trazer a essência da hospitalidade para os encontros 'virtuais'.

Pode-se refletir que a hospitalidade virtual possa ser contemplada na hospitalidade em rede e, muitas vezes, seja mais aparente funcionando como mecanismo para estabelecer os primeiros contatos entre os estranhos, possíveis hóspedes e anfitriões.

A hospitalidade em rede é uma proposta de discussão dos fenômenos sociais em que as relações hóspedes e anfitriões são alternadas e mediadas por plataformas na web e demais tecnologias a partir de diversos usos. É mais abrangente do que a hospitalidade virtual, uma vez que procura discutir tais relações sem distinção entre os contextos (online e offline). Já se parte do pressuposto de que se vive numa sociedade na qual o uso da tecnologia faz parte da vida comunal e é apropriada pelos indivíduos que lhe atribuem diferentes usos e significados.

A principal reflexão é que a hospitalidade em rede traz a possibilidade de diálogo e análise entre várias práticas de consumo colaborativo no contexto do turismo sob as quais os aspectos relacionais estão intrínsecos e se sobrepõe a outros tipos de trocas ainda que sejam monetárias.

Outros autores também mencionam as transformações sociais contemporâneas que podem ser estendidas à Network Society e complementam a perspectiva. Bawens (2010), por exemplo, destaca que nesse tipo de sociedade, há o aumento da individualização na mesma proporção da necessidade de reconstruir as identidades coletivas por meio da relationality peer to peeer ou relacionalidade aos pares. Assim, tanto os indivíduos estão investindo em suas interações online, quanto estão tornando-as extensões das relações sociais por meio das interações offline entre pares, a fim de construir e pertencer a grupos sociais e de referência. Complementando, Richards (2013) reforça que esta nova relacionalidade não é construída a partir 

2016.

de critérios como idade, classe ou estilo de vida, mas em torno de objetivos compartilhados entre os indivíduos.

Baek, Manzini e Rizzo (2010) pontuam que nem toda interação produz relacionalidade ou conexão temporária entre os indivíduos. A qualidade relacional do sujeito coletivo dessas interações reside no fato dos usuários colaborarem entre si para atingirem um objetivo comum. Sem essa percepção, ocorrerá uma mera participação sem necessariamente evocar uma relacionalidade. Constata-se, portanto, que os recursos da sociedade em rede facilitaram a (re)construção de identidades coletivas por meio das redes sociais e do compartilhamento de objetivos comuns.

Boswijk, Thijssen e Peelen (2007) chamam atenção para o surgimento das comunidades e a possível era da terceira geração da experiência. Enquanto as primeiras gerações consideram que a economia, o mercado e, portanto, as empresas podem direcionar o significado das experiências e facilitar a (co)criação de valor; na terceira geração, a economia é apenas parte do contexto e todo o processo de significação dado pelo indivíduo ocorre em contato com outros, no caso, sua rede social. Em busca de experiências autênticas, os consumidores, ou melhor, os indivíduos, constroem uma demand-driven ou demanda impulsionada e passam a organizar-se em redes nas quais criam e recriam valor a partir das interações sociais e necessidades não atendidas.

Verifica-se, portanto, que o contexto social no qual o consumo colaborativo se desenvolve é aquele em que os indivíduos estão buscando e alterando suas formas sociais de se relacionar tentando (re) produzir e consumir novos laços e relações sociais em torno de objetivos compartilhados e/ou criar valor aos pares por meio das interações sociais.

A sociedade em rede potencializou as transformações sociais, além disso, uma vez que contexto social e econômico possui limites tênues e/ou inseparáveis, as práticas colaborativas convergem com esta sobreposição. Reconhece-se que, além de consumidores, os indivíduos são membros de uma sociedade/organização e que participam de um contexto social que exerce influência sobre os seus processos de significação.

A partir da discussão exposta, o tópico seguinte apresenta algumas práticas do consumo colaborativo que possibilitam a sua interpretação como um consumo relacional no contexto do turismo. 


\section{O consumo colaborativo e relacional no contexto do turismo: proposição de um framework}

Este tópico tem como propósito apresentar algumas características do consumo colaborativo enquanto uma forma de consumo relacional no contexto do turismo. Essa proposta ganha destaque em função de se ter verificado, a partir da revisão de literatura, que a maioria dos conceitos associados ao consumo colaborativo está ligada às relações de troca mercantil como unidade de análise e/ou a participação (colaboração) online.

Dentre os conceitos e abordagens estudados, a colaboração online mediada pela tecnologia, aparece como vetor para a criação e desenvolvimento de conceitos, sistemas, serviços, e ideias associadas à participação ou colaboração online de usuários, consumidores e outros grupos (BRABHAM, 2008; ROWLEY, KUPIEC-TEAHAM, LEEMING, 2007; TAPSCOTT, WILLIAMS, 2008). Alguns outros autores tratam a colaboração como uma maneira de realizar transações comerciais ou como forma de compartilhamento de tangíveis (transferência de propriedade) mediada pela tecnologia (BELK, 2007, 2010; BOTSMAN, ROGERS, 2010; MANZINI, 2010).

Ainda há alguns autores (BAEK et al, 2010; CIPOLLA, MELO, MANZINI, 2009; CIPOLLA, 2009, 2007) que iniciam a discussão sobre os aspectos colaborativos existentes no design de serviços para além da interação mediada pela tecnologia, baseando-se na participação ou coparticipação de todos os atores sociais. No entanto, apesar de iniciarem a discussão da colaboração como parte do serviço, a abordagem que utilizam não se fundamenta na aproximação da colaboração como processo relacional e social de consumo em si e, tampouco, no contexto do turismo, cujo argumento é a proposta de reflexão deste artigo.

Em virtude de indicação da existência de uma lacuna interpretativa sobre o consumo na perspectiva relacional e considerando-se a possibilidade de contribuição deste estudo a partir das reflexões anteriormente apresentadas sobre o tema, propõe-se um framework teórico que tem como objetivo uma reinterpretação teórica que busca explicar os aspectos sociais e relacionais do consumo colaborativo no contexto do turismo, baseando-se na perspectiva da hospitalidade em rede de Molz (2014) e da sociabilidade em rede de Wittell (2001).

O quadro 1, apresentando a seguir, resume as principais proposições da Network Sociality, de Wittel (2001), e da Network Hospitality, de Molz (2014) e segue com a respectiva reinterpretação proposta neste ensaio teórico aplicando-a ao consumo colaborativo e relacional. 
Quadro 1 - Proposição do framework do Consumo Colaborativo e Relacional a partir da contraposição com a Network Sociality e Network Hospitality

\begin{tabular}{|c|c|c|}
\hline Network Sociality (Wittel, 2001) & Network Hospitality (Molz, 2014) & Consumo colaborativo e relacional \\
\hline $\begin{array}{l}\text { Individualização (integração e } \\
\text { desintegração às redes, } \\
\text { pertencimento temporário e fatual } \\
\text { do indivíduo, autônomo, em busca } \\
\text { seus objetivos). }\end{array}$ & $\begin{array}{l}\text { Compartilhamento com estranhos. } \\
\text { Gestão da reputação. As moedas de } \\
\text { troca tomam diferentes formas, tais } \\
\text { como as explícitas, dinheiro, objetos } \\
\text { e, as implícitas, como os diálogos, } \\
\text { rituais, entre outras. }\end{array}$ & $\begin{array}{l}\text { 1.1 Gestão do capital } \\
\text { reputacional, diferentes } \\
\text { moedas de troca (quando } \\
\text { existem), a moeda dinheiro } \\
\text { não é central. Consumo na } \\
\text { forma de uma } \\
\text { sociabilidade que habilita } \\
\text { novas configurações entre } \\
\text { vida comunal e consumo. } \\
\text { Novas formas de arranjos } \\
\text { diádicos, triádicos, etc. } \\
\text { consumer to business, } \\
\text { consumer to consumer. }\end{array}$ \\
\hline $\begin{array}{l}\text { Relações efêmeras e intensas: tanto } \\
\text { em negócios quanto na vida social, } \\
\text { muitas pessoas se encontram por } \\
\text { curto espaço de tempo e tem de } \\
\text { tomar decisões com quem } \\
\text { estabelecer contato/relações, quanto } \\
\text { tempo dedicar a cada um e outras } \\
\text { decisões relativas. }\end{array}$ & $\begin{array}{l}\text { Sentindo-se como um hóspede: Os } \\
\text { encontros onde emergem as relações } \\
\text { temporárias, também geram uma } \\
\text { intimidade temporária. }\end{array}$ & $\begin{array}{l}\text { 1.2 Interação e colaboração a } \\
\text { partir sentimentos como a } \\
\text { empatia. Plataformas } \\
\text { habilitam e potencializam } \\
\text { as interações e os novos } \\
\text { arranjos produtivos e } \\
\text { sociais. A empatia parece } \\
\text { um ingrediente que } \\
\text { influencia a interação e a } \\
\text { colaboração para os } \\
\text { encontros. Os papéis se } \\
\text { alternam. }\end{array}$ \\
\hline $\begin{array}{l}\text { Da narrativa para a informação: não } \\
\text { há troca de narrativas, mas de } \\
\text { informação. }\end{array}$ & $\begin{array}{l}\text { Engenharia da aleatoriedade: critérios } \\
\text { de escolha para estabelecer algum } \\
\text { tipo de sociabilidade transita entre a } \\
\text { similaridade e a aleatoriedade. }\end{array}$ & $\begin{array}{l}\text { 1.3 Critérios de escolha } \\
\text { baseados na similaridade } \\
\text { ou aleatoriedade entre os } \\
\text { pares, as narrativas são } \\
\text { apresentadas por meio de } \\
\text { artefatos e fragmentos. }\end{array}$ \\
\hline $\begin{array}{l}\text { Assimilação entre trabalho e lazer } \\
\text { em ambas direções e dimensões. }\end{array}$ & $\begin{array}{l}\text { Pop-up: há assimilação entre trabalho } \\
\text { e lazer como resultado da } \\
\text { reconfiguração sócio espacial da vida } \\
\text { social cotidiana. }\end{array}$ & $\begin{array}{l}\text { 1.4 Dimensões turvas entre } \\
\text { trabalho, lazer, } \\
\text { sociabilidade, articulação } \\
\text { sócio territorial. }\end{array}$ \\
\hline $\begin{array}{l}\text { Tecnologia: a presença da } \\
\text { tecnologia na vida pessoal e } \\
\text { profissional de forma cada vez mais } \\
\text { imersa provém mobilidade e formas } \\
\text { emergentes de (co) presença }\end{array}$ & $\begin{array}{l}\text { Hóspedes sem anfitriões: todos são } \\
\text { potenciais convidados e hóspedes nos } \\
\text { encontros. Além disso, os papéis se } \\
\text { alternam na interação offline. }\end{array}$ & $\begin{array}{l}1.5 \text { A tecnologia como ponte } \\
\text { para as interações face a } \\
\text { face: } \\
\text { A tecnologia habilita e } \\
\text { potencializa a participação } \\
\text { de todos em um } \\
\text { engajamento mútuo que }\end{array}$ \\
\hline
\end{tabular}




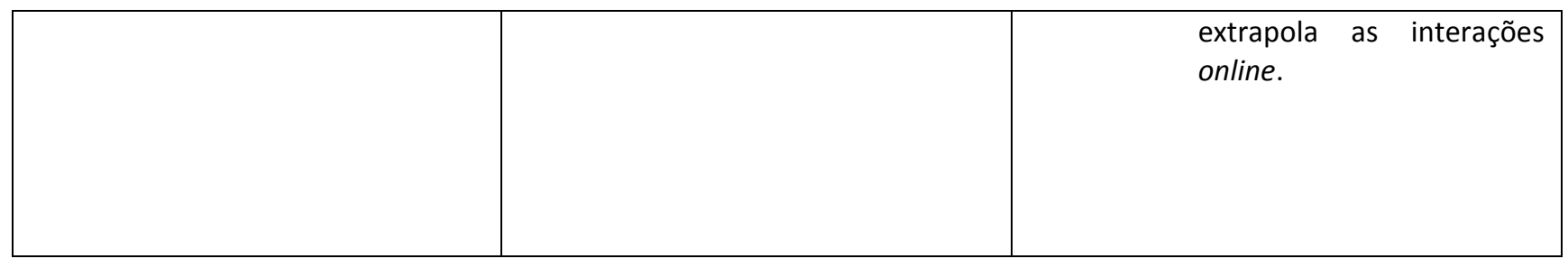

Fonte: Wittel (2001), Molz (2014), B. G. Matos, Barbosa \& Matos (2015).

No quadro 1, fez-se a exposição das posições de Wittel (2001) e Molz (2014) sobre Network Sociality e a Network Hospitality, sumarizou-se as considerações para o consumo colaborativo relacional, respectivamente, nas colunas 1, 2 e 3. Um maior detalhamento, bem como a apresentação das proposições desde a discussão é exposto abaixo.

\section{Capital reputacional, diferentes moedas de troca (quando existem), arranjos} variados (diáticos, triáticos, etc)

Enquanto a Network Sociality (WITTEL, 2001) enfatiza a individualização, a Network Hospitality (MOLZ, 2014) gira em torno do compartilhamento, também chamado de sharing. Sharing online é traduzido como o retorno ao compartilhamento, a partir das interações online para o "mundo offline", é o caso dos sites peer-to-peer que os indivíduos utilizam para compartilhar bicicletas, vagas em estacionamento, livros, não somente com família e amigos, mas estranhos do mundo todo (MOLZ, 2014). A moeda de troca pode ser monetária, mas nem sempre vem em forma material, há possibilidades implícitas de troca como: compartilhamento de diálogo, sociabilidade e rituais.

Na Network Hospitality (MOLZ, 2014) as plataformas online de reputação corroboram para estranhos estabelecerem, entre eles, o senso de confiança. É o caso do consumo colaborativo, onde a participação dos indivíduos gira mais em torno do capital reputacional do que do capital econômico. O capital reputacional é a avaliação social de determinado indivíduo.

Para Wittel (2001), a concepção de valor é relativa, sendo a individualização uma das características da Network Sociality, o autor ainda enfatiza que é responsabilidade individual criar novos laços sociais. Já para Molz (2014), na Network Hospitality, a individualização toma o formato da gestão do capital reputacional. Os indivíduos constroem seus laços sociais por meio da gestão da reputação, assim, o capital reputacional, não o monetário, é a moeda de domínio. 

2016.

No consumo colaborativo relacional no contexto do turismo, estão presentes os mesmos aspectos da gestão da reputação constantes na Network Hospitality. É o caso do Trip Advisor ${ }^{7}$, site de informações turísticas onde o conteúdo é gerado pelos próprios usuários, que deixam sua opinião e avaliação sobre locais, cidades, restaurantes e pontos visitados em diferentes partes do mundo para outros viajantes ou demais pessoas interessadas que possam se beneficiar de tal informação. O valor das informações fornecidas é avaliado pelos indivíduos que leem e participam da construção da reputação dos usuários, empresas, pontos turísticos.

As características da Network Sociality e Hospitality imprimem o que chama-se inovação social no consumo colaborativo relacional ao promoverem novos arranjos. De acordo com Manzini (2010), a inovação social altera as formas de viver, tais como hábitos de vida, hábitos de consumo e a produção destas novas formas surgem baseadas mais em relações sociais do que a partir do topo das grandes empresas, assim como mais das relações marginais do que das relações centrais. Nesse contexto, novas reconfigurações aparecem entre a vida comunal e o consumo dos ditos estilos colaborativos (BOTSMAN, ROGERS, 2010).

Um outro exemplo da ressignificação entre vida comunal e consumo e compartilhamento com estranhos é a plataforma Trocacasa.com. Nesse site, usuários de diferentes localidades que desejam viajar para algum destino, permutam, por um período determinado, de lar. Os usuários não se conhecem pessoalmente e, mesmo após a troca de casa, podem nunca estabelecer um contato presencial. Neste caso, não há moeda de troca envolvida.

A inovação citada acima promove arranjos diáticos, triáticos, dentre outros. Esses arranjos híbridos são formados por indivíduos, empresas, governo e organizações não governamentais. A partir do exposto, estabelece-se a primeira proposição do consumo colaborativo e relacional:

Proposição 1: O consumo se apresenta na forma de uma sociabilidade que habilita novas configurações entre vida comunal e consumo, a partir da gestão do capital reputacional, diferentes moedas de troca e novos arranjos entre consumidores e provedores.

\footnotetext{
${ }^{7} \mathrm{O}$ tripadvisor funciona como uma plataforma colaborativa em que viajantes e locais podem avaliar pontos turísticos, hospedagem, bares, restaurantes e demais localidades que tenham visitado. As avaliações servem para construir a reputação dos pontos e organizações. Isso pode influenciar a decisão daqueles que buscam por este serviço. $\mathrm{O}$ acesso e colaboração na plataforma é gratuito.
} 
As práticas colaborativas requerem interações entre diversos públicos, tais como, usuários, consumidores, empresas, organizações não governamentais e governo que desenvolvem formas emergentes de sociabilização, a partir da colaboração, de rituais, padrões e comportamentos de consumo não convencionais, nas quais o capital reputacional exerce um papel importante.

No consumo colaborativo e relacional não há obrigatoriedade da existência de moeda de troca, não sendo este, necessariamente, o elemento central. E, quando existe, pode apresentar diferentes representações (tais como: tempo, crédito virtual, dinheiro).

\section{A interação e a colaboração para os encontros são mediadas por critérios prévios}

Wittel (2001) destaca as relações efêmeras, porém, intensas, que caracterizam a cooperação e os laços sociais estabelecidos e restabelecidos rapidamente em função dos projetos de trabalhos temporários ou de curta duração. O mesmo ocorre em situações fora do trabalho, na vida social. Muitas pessoas se encontram em um curto espaço de tempo e isso faz com que tenham que tomar decisões de com quem conversar, quanto tempo dedicar a cada contato, entre outras opções.

Na Network Hospitality (MOLZ, 2014), por sua vez, acrescenta que a intimidade é gerada rapidamente nesses encontros, onde tanto anfitriões quanto hóspedes estabelecem comportamentos e ações de acordo, e em consequência, das interações e do tipo de relação que constroem um com o outro.

No consumo colaborativo e relacional os encontros são mediados por plataformas, redes sociais e aplicativos que habilitam e potencializam a colaboração e as interações em novos arranjos produtivos e sociais. Empatia parece um ingrediente capaz de gerar confiança e fortalecer a interação entre os indivíduos. Uma vez que confiança e intimidade são construídas e variam de interação para interação, seus resultados também podem ter diferentes significados para os participantes.

Exemplificando o consumo colaborativo e relacional, pode-se mencionar o Bliive, plataforma baseada em banco de horas na qual os usuários oferecem algum serviço presencial que, quando prestados, tem como consequência a geração de créditos a serem utilizados na aquisição de outros serviços ofertados na plataforma. Amigo para ouvir desabafo, companhia para ir ao cinema, conhecer a cidade do Recife de bicicleta, dicas de uma mochileira, são 
exemplos, dentre outros, de ofertas disponíveis na plataforma. Há a emergência de um processo interacional que envolve construção de intimidade, confiança, relacionalidade e escolha para os encontros que é mediada por uma avaliação empática. Diante do exposto, segue-se a segunda proposição para o consumo colaborativo e relacional:

Proposição 2: A empatia aparece como possível elemento para promover a interação, colaboração e relacionalidade nos encontros entre os indivíduos.

Podem surgir então, novos tipos de colaboração, serviços e sistemas a partir das possíveis interações. A exemplo, o Couchsurfing, em que é provável que um hóspede cozinhe para o seu anfitrião durante sua estadia. As interações permitem alternância entre papéis cada vez mais turvos e sobrepostos no processo de colaboração em que os termos tradicionais de serviços, como prestador e consumidor, por exemplo, não se enquadram mais claramente nesse contexto ou são encontrados de forma híbrida.

\section{Critérios de escolha baseados na similaridade ou aleatoriedade entre os pares e as narrativas significadas por meio de artefatos e fragmentos.}

A Network Sociality, de Wittel (2001), não é baseada em uma narrativa comum e compartilhada. Os laços sociais são construídos menos baseados nas relações hierárquicas e mais na complexidade. $\mathrm{O}$ autor destaca uma mudança da sociabilidade baseada no compartilhamento da experiência para o compartilhamento de informação. A mobilidade e a velocidade parecem razões para esta mudança da experiência baseada na sociabilidade para a sociabilidade informacional.

Molz (2014) coloca que os membros encolhem com quem irão realizar interações e complementa que a forma como estes escolhem seus pares interacionais vai além dos critérios de possuírem características comuns, ressaltando que há também a presença de critérios aleatórios. O tipo de sociabilidade que emerge na Network Sociality transita entre estas duas tensões: ora indivíduos se relacionam pela similaridade ora pela aleatoriedade.

No consumo colaborativo e relacional, há a presença da aleatoriedade descrita por Molz (2014), nesse sentido, a reputação, pode ser um critério para a redução do risco, mas nem sempre segue previsibilidade e é adotada como critério por todos os membros.

O rent a local friend, serviço que propõe um turismo guiado por pessoas que se supõe autóctones, oferece a possibilidade da escolha de guias locais baseada em seus perfis 

2016.

apresentados na rede, que trazem características como línguas que falam, interesses e hobbies, proposta da experiência local, dentre outros. Os critérios para se escolher um local friend pode variar dentre aqueles que falem o mesmo idioma (similaridade) e/ou que possam oferecer uma experiência totalmente distinta daquelas que o turista possui (aleatoriedade - pode-se não saber cozinhar, mas a experiência de aprender a cozinhar uma comida típica pode ser um critério de escolha).

Quanto ao aspecto transacional da narrativa para a informação, argumentado por Wittel (2001), tem-se uma controvérsia. Concorda-se com a complexidade envolvida nas narrativas, porém, as informações, do ponto de vista das autoras deste artigo, são um conjunto de fragmentos que compõem novas narrativas. Assim, não há o fim das narrativas, mas a recriação destas por meio de fragmentos gerados em interações, colaboração, atividades online e offline. A exemplo disso, tem-se o uso e a construção de vídeos ou outros artefatos que representam a estória destas interações. Como exemplo, pode-se citar o prosumerismo, onde a produção e consumo de conteúdo digital é simultânea e está cada vez mais relacionada às interações. As plataformas que descrevem comidas e fotos de pratos incentivam a colaboração dos leitores que completam as informações com mais informação, depoimentos e/ou outras imagens ou outro tipo de artefato, como vídeos. Estas possibilidades são fragmentos que compõem a ressignificação das narrativas. Assim sendo, sugere-se uma terceira proposição:

Proposição 3: Os critérios de escolha com quem interagir são baseados na similaridade ou aleatoriedade entre os pares e as narrativas são representadas por meio de fragmentos e artefatos.

Fragmentos de informação compõem novos formatos de narrativas, tais como a participação, a colaboração e a criação de artefatos, tanto para prover o engajamento como símbolo do consumo colaborativo, do intangível, como para a coconstrução enquanto marco no processo. As decisões dos indivíduos alternam-se entre critérios baseados na similaridade dos pares e critérios aleatórios.

\section{Dimensões turvas entre trabalho, lazer, sociabilidade e articulação sócio territorial}

De acordo com Wittel (2001) na Network Sociality existe uma maior associação entre trabalho e lazer em ambas as direções e dimensões. Tanto os aspectos do lazer estão mais 
MATOS, B.G; BARBOSA, M.L.A.; MATOS, M.B.A. Consumo Colaborativo e Relacional No Contexto do Turismo (...). Revista Hospitalidade. São Paulo, volume 13, n.01, p. 218-241, agosto de 2016.

presentes no trabalho quanto o oposto. Tem-se como exemplo, o design e as formas de planejamento que associam técnicas criativas e brincadeiras no trabalho ou, por exemplo, encontros de trabalho em pubs. O objetivo implícito desta associação é obter uma melhor performance, consequentemente esta associação reduz os limites entre trabalho e vida particular e entre amigos e colegas de trabalho.

Molz (2014) corrobora com a proposição de Wittel (2001) sobre os limites tênues entre lazer e trabalho, porém, não se foca, inicialmente, em uma análise somente espacial. Para Molz (2014), essa discussão abre o debate sobre a reconfiguração do espaço temporal da vida social cotidiana em sociedades saturadas pela tecnologia. Por exemplo, a comunicação móvel e as tecnologias em rede mediam novas formas de copresença e tipos novos de espaços híbridos, tais como, eventos, hotéis temporários. Como destaca Molz (2014), além dos espaços, os encontros entre estranhos são mais fluídos e rizomático, pois não acontece apenas em locais públicos, mas também em espaços privados como o lar e a vizinhança das pessoas.

No consumo colaborativo e relacional, além de lazer e trabalho possuírem limites turvos (WITTEL, 2001) e do sócio espaço temporal estar reconfigurado (Molz, 2014), a articulação territorial é um aspecto importante, conforme pode ser observado no exemplo abaixo.

$\mathrm{O}$ rent a local friend é uma plataforma que oferece um serviço relacional de turismo guiado e que está presente em quatro continentes. Os usuários provedores são pessoas que adoram viajar e compartilhar experiências, se interessam por interações humanas e atuam profissionalmente em áreas não necessariamente ligadas ao turismo e que fizeram do serviço de turismo guiado uma forma de associar trabalho e lazer. Além disso, o fato de não atuarem na área não parece ter muita influência, pois o serviço principal é a locação de um amigo pertencente ao lugar escolhido para visitar e não a contratação de um guia tradicional. Quer dizer, não são, normalmente, profissionais da área de turismo que prestam esse tipo de atendimento, mas pessoas que tem vontade de interagir com outros e mostram a cidade em que vivem ao visitante sob uma perspectiva mais local e menos turística. A programação e os roteiros são decididos em comum acordo. Vê-se aqui a emergência de espaços híbridos, pois existe o potencial do usuário consumidor interagir com o usuário provedor ao compartilhar espaços sociais e vice versa. Geralmente, os usuários consumidores, são pessoas que desejam ter um contato mais relacional, íntimo e autêntico enquanto viajam. As interações e a colaboração emergem durante os 
encontros. Importante ressaltar, que além dos aspectos mencionados por Molz (2014) e Wittel (2001), há a articulação territorial no consumo colaborativo e relacional.

A articulação territorial no consumo colaborativo relaciona-se a um país, um estado, uma comunidade, com limites não necessariamente físicos, mas também sociais. No caso do Rent a local friend, o exemplo de uma articulação com o território são os locais, bairros e cidades os quais os usuários consumidores visitam. A localidade é, por vezes, um espaço coconstruído, onde características intangíveis são atribuídas por aqueles que são do lugar, tornando esses aspectos, às vezes, mais relevantes que suas próprias características tangíveis. Um local não turístico, alternativo e/ou fora do circuito de visita em massa, pode tornar-se referência de um destino e constituir um elemento simbólico atribuído pelo visitante.

Outro exemplo, é o Mealsharing, plataforma que habilita o compartilhamento de comida ao redor do mundo e permite que usuários tenham a experiência de fazer uma refeição na casa e na companhia de um autóctone. A localização ou o bairro, neste caso, não necessariamente tem relação com os pontos turísticos da cidade, o que pode gerar uma dispersão do fluxo do turismo para outras áreas não convencionais.

Outro caso semelhante, na essência, e que funciona sob a mesma lógica do Mealsharing é o Couchsurfing, uma organização não governamental sem fins lucrativos que agrega em uma comunidade virtual hóspedes e viajantes do mundo inteiro. Por meio da plataforma, usuários oferecem espaço em seu domicílio para hospedar viajantes, neste caso, ressalta-se a experiência da acolhida entre um hospedeiro e um hóspede que, apesar da nomenclatura utilizada, pode ir além da oferta de um sofá para dormir, mas pode incluir aspectos relacionais que englobam o compartilhamento de refeições ou visita a recantos de uma cidade, não necessariamente integrantes de um circuito turístico clássico. Estabelece-se, portanto, a quarta proposição:

Proposição 4: Dimensões nebulosas entre trabalho, lazer, sociabilidade e articulação sócio territorial.

\section{A tecnologia como ponte para as interações face a face}

A Network Sociality está imersa em uma sociedade que usa a tecnologia para administrar negócios e estabelecer relações. É a sociedade do movimento, da mobilidade em que a tecnologia é utilizada com o intuito de prover mobilidade (WITTEL, 2001). Nesse contexto em que as 

2016.

tecnologias estão cada mais presentes nas relações face a face, torna-se difícil definir um limite entre as interações presenciais e não presenciais.

A decorrência da reconfiguração sócio espacial é a reconfiguração dos papéis desempenhados pelos hóspedes e anfitriões, conforme destaca Molz (2014) ao tratar da hospitalidade. Não há como separar infraestrutura da comunicação neste contexto. Se há emergência de novas formas de comunicação e de organização, há também a emergência de papéis híbridos. Para Molz (2014) na Network Hospitality todos são potenciais convidados ou anfitriões e muitos dos anfitriões que integram o Couchsurfing, por exemplo, não são autóctones nas cidades em que ofertam hospedagem, muitas vezes são expatriados, imigrantes ou pessoas vivendo temporariamente no local onde escolhem para serem hospedeiros.

No Consumo Colaborativo e Relacional, além dos papéis se alterarem e possuírem esta mutualidade (todos são potenciais hóspedes e anfitriões), a tecnologia aparece como uma ponte para que os encontros ocorram para além das interações nas plataformas.

O Partywithalocal.com, por exemplo, é uma rede que sugere a possibilidade de um turista se conectar na plataforma e encontrar alguém de um determinado lugar com quem possa sair para uma festa. A plataforma habilita, assim, o encontro face a face. Destas considerações, segue-se a quinta proposição:

Proposição 5: A tecnologia surge como ponte para as interações face a face.

Em função das perspectivas teóricas revistas neste ensaio, com base na literatura acessada, e dos exemplos de práticos de consumo colaborativo e relacional apresentados, buscouse lançar algumas proposições de caráter teórico com o objetivo de contribuir para uma melhor reflexão e compreensão dos aspectos ou requisitos fundamentais que caracterizam as práticas de consumo colaborativo no turismo.

Considera-se, nessa perspectiva, que os aspectos fundamentais presentes no consumo colaborativo enquanto processo relacional no contexto do turismo são: a gestão do capital reputacional, diferentes moedas de troca (quando existem), arranjos variados (diáticos, triádicos, etc); interação e colaboração são mediadas por critérios prévios como a empatia para os encontros; critérios de escolha baseados na similaridade ou aleatoriedade ente os pares, e as narrativas significadas por meio de artefatos e fragmentos; dimensões nebulosas entre trabalho, lazer, sociabilidade, articulação sócio territorial; e a tecnologia como ponte para as interações face a face. 

2016.

Apresentadas as proposições resultantes das reflexões sobre o consumo colaborativo e relacional no contexto do turismo, parte-se para as considerações finais deste ensaio.

\section{Considerações Finais}

A proposta deste ensaio foi gerar uma reflexão sobre o consumo colaborativo e relacional a partir da compreensão das interseções entre uma perspectiva econômica e social no contexto do turismo. Quanto ao primeiro objetivo, "compreender os conceitos de consumo colaborativo e sharing”, a literatura bibliográfica indica que é possível dar diferentes abordagens ao tema. No entanto, há a prevalência da delimitação dos conceitos chaves a partir da lógica financeira (comercial) de transferência de propriedade/posse e acesso, e há limitadas reflexões a respeito das sobreposições entre os elementos sociais e econômicos como processos socialmente construídos, seguindo uma lógica sociológica que contemple as interações entre as pessoas que participam destas práticas.

No que se refere ao segundo objetivo, "descrever a sociabilidade e hospitalidade em rede propostas por Wittel (2001) e Molz (2014), respectivamente", apresentadas no decorrer do ensaio, possibilitou também o desenvolvimento do terceiro objetivo, "propor uma reflexão dos aspectos fundamentais que caracterizam o consumo colaborativo e relacional no contexto do turismo. A discussão do quadro teórico sociológico proposto pelos autores (WITTEL, 2001; MOLZ, 2014), permitiu trazer as principais características para uma ampliação dos conceitos e uma melhor reflexão das práticas do consumo colaborativo no contexto do turismo.

Nesse sentido, e como forma de contribuição, conclui-se que este ensaio ofereceu elementos discursivos para expandir a abordagem do consumo colaborativo e relacional na área. Isso torna-se importante, na medida em que se constata que este tipo de consumo está assentado em uma base eminentemente relacional e há a necessidade de construção acadêmica que contraste perspectivas de áreas diferentes de modo a evoluir no campo.

As limitações do trabalho refletem a própria escolha metodológica, de natureza ensaística, fazendo-se necessário uma validação das proposições discutidas em pesquisa empírica, no contexto do turismo. Bem como, ressalta-se que as assertivas expostas no decorrer da explanação das proposições não são exaustivas. 
Além de validação das premissas apresentadas, sugere-se alguns temas para pesquisas futuras, a saber: investigar quais tipos de colaboração e níveis de envolvimento emergem do consumo colaborativo e relacional; de que forma o valor é (co) construído pelos indivíduos também é outro aspecto para futuras pesquisas.

Outro ponto relevante é identificar e mapear, a partir das práticas, os tipos de moedas de troca; descrever como organizações e indivíduos gerenciam seu capital reputacional e os diferentes mecanismos que utilizam. Além da empatia, quais motivações e critérios (sejam baseados na aleatoriedade e/ou similaridade) são adotados pelos sujeitos ao estabelecer as primeiras interações e conexões com os outros? Quanto à articulação sócio territorial, esta teria um fundamento sustentável ou ocasional, estariam os sujeitos mais orientados às práticas sustentáveis de consumo ou o aspecto sustentável pode ser ocasional? Ainda que o consumo colaborativo tenha uma base relacional, como os espaços dos encontros são construídos (há influência dos aspectos do ambiente na experiência? Ou é pouco relevante?).

As considerações desta discussão sinalizam para possibilidades de reflexão em diferentes campos. Na economia, as premissas das trocas utilitárias defendidas pela microeconomia não são suficientes para explicar e compreender os modelos híbridos que relativos ao consumo colaborativo e relacional. De que maneira as práticas colaborativas e relacionais levam a mudanças no comportamento do consumidor e/ou turista e reconfiguração dos modelos para além da transição dos papéis de consumo. A formação da reputação dos indivíduos colaborativos; o processo de construção da confiança e a intimidade estabelecida entre os pares são aspectos apenas mencionados neste ensaio, mas de relevância para a compreensão do fenômeno, tanto em campos que estudam o consumo como àqueles que estudam o comportamento social dos indivíduos e áreas correlatas.

As implicações para os pesquisadores de áreas afins e correlatas sugere a necessidade de compreender e validar as práticas colaborativas sob diferentes lógicas (comerciais, sociais), buscar as motivações dos agentes (usuários, empresas, governo, organizações não governamentais). Há implicações diretas sob como é planejado e elaborado ofertas de sistemas turísticos.

Vale-se ainda da necessidade de discutir as implicações jurídicas (das formas híbridas, de forma a proteger todos que participam das práticas colaborativas usufruem), sociais (quais as implicações para a sociedade em geral, os países, a população dos destinos, as localidades), 
econômicas (quais os impactos para a economia dos sistemas que propõem o uso de diferentes moedas) e culturais (há a indicação de uma cultura global ou globalização da cultura).

A discussão explanada neste ensaio é relevante para pesquisadores na área de turismo, hospitalidade e administração que atuem com pesquisa, planejamento e execução de atividades turísticas, especialmente àquelas nas quais há maior contato e envolvimento com os turistas e receptores e permitem o desenrolar de relações entre a vida comunal e o consumo. É possível refletir sobre diversas moedas de troca que possam incentivar a visitação e adesão a diferentes atividades no destino. $\mathrm{O}$ uso de narrativas e artefatos podem auxiliar no engajamento e promoção das estórias do destino e dos seus locais. As interlocuções entre trabalho, lazer e sociabilidade com a articulação sócio territorial permite pensar possibilidades mais sustentáveis de desenvolvimento turístico e local as quais envolva os residentes do destino.

\section{Referências}

BAEK, J. S.; MANZINI, E.; RIZZO, F. Sustainable collaborative services on the digital platform: Definition and application. In Design Research Society International Conference Montreal. p. 123-131, 2010.

BAWENS, M. Peer-to-Peer Relationality: the city and anonymity. Disponível em: <http://w2.bcn.cat/bcnmetropolis/arxiu/en/pagea8ed.html?id=23\&ui=424>. Acesso em: 24 jan. 2014.

BELK, R. You are what you can access: Sharing and collaborative consumption online. Journal of Business Research, v. 67, n. 8, p. 1595-1600, 2013.

. Sharing. Journal of Consumer Research, v. 36, n. 5, p. 715-734, fev. 2010.

. Why Not Share Rather Than Own? The ANNALS of the American Academy of Political and Social Science, v. 611, n. 1, p. 126-140, 1 maio 2007.

BOSWIJK, A.; THIJSSEN, T.; PEELEN, E. The experience economy: a new perspective. Pearson Education, 2007.

BOTSMAN, R.; ROGERS, R. What's mine is yours: The rise of collaborative consumption. New York: Harper Collins, 2010.

BRABHAM, D. C. Crowdsourcing as a Model for Problem Solving: An Introduction and Cases. Convergence: The International Journal of Research into New Media Technologies, v. 14, n. 1, p. 75-90, 2008. 
MATOS, B.G; BARBOSA, M.L.A.; MATOS, M.B.A. Consumo Colaborativo e Relacional No Contexto do Turismo (...). Revista Hospitalidade. São Paulo, volume 13, n.01, p. 218-241, agosto de

CAMARGO, L. O. Os domínios da hospitalidade. Hospitalidade: cenários e oportunidades. São Paulo: Pioneira Thomson Learning, p. 61-71, 2008.

CAMARGO, L. O. Os interstícios da hospitalidade. Revista Hospitalidade, v. XII, n. especial, p. 42-69, 2015.

CASTELLS, M. The rise of the network society. The information age: economy, society, and culture. Malden Mass: Blackwell, v. 1, 1996.

CIPOLLA, C. Designing for interpersonal relational qualities in services. A model for service design theory and practice (PhD thesis in Industrial Design). Milan. Politecnico di Milano University, 2007.

Relational services: service design fostering sustainability and new welfare models. In Proceedings of the 2nd International Symposium on Sustainable Design (II ISSD). Disponível em: 〈http://portal. anhembi. br/sbds/anais/ISSD2009-015. pdf〉. Acesso em: dez, 2009.

CIPOLLA, C.; MELO, P.; MANZINI, E. Collaborative services in informal settlements: a social innovation case in a pacified favela. In Rio de Janeiro. Social Frontiers Conference, London, 2009.

FELSON, M.; SPAETH, J. L. Community Structure and Collaborative Consumption. American Behavioral Scientist, v. 21, n. 4, p. 614-624, 1978.

MANZINI, E. Making things happen: social innovation and design. Design Issues, v.30, n. 1, 57-66, 2010.

MOLZ, J. G. Toward a network hospitality. First Monday, v. 19, n. 3, 2014.

RICHARDS, G. Creativity and tourism in the city, Current Issues in Tourism. Disponível em: <http://dx.doi.org/10.1080/13683500.2013.783794>. Acesso em: 24 fev. 2014,2013.

ROWLEY, J.; KUPIEC-TEAHAN, B.; LEEMING, E. Customer community and co-creation: a case study. Marketing Intelligence \& Planning, v. 25, n. 2, p. 136-146, 2007.

SHIRKY, C. Here comes everybody: The power of organizing without organizations. Penguin, 2011.

TAPSCOTT, D.; WILLIAMS, A. D. Wikinomics: How mass collaboration changes everything. Penguin, 2008.

URRY, J. Social networks, travel and talk. The British journal of sociology, vol. 54, n. 2, p. 155-175, 2003. 
MATOS, B.G; BARBOSA, M.L.A.; MATOS, M.B.A. Consumo Colaborativo e Relacional No Contexto do Turismo (...). Revista Hospitalidade. São Paulo, volume 13, n.01, p. 218-241, agosto de 2016.

WITTEL, A. Toward a network sociality. Theory, culture \& society, vol. 18, n. 6, p. 51-76, 2001.

Recebido: 04/02/2016

Reavaliado em: 12/06/2016

Aprovado em: 07/10/2016 